\title{
Normalization of brain morphology after surgery in sagittal craniosynostosis
}

\author{
Eric D. Brooks, MD, MHS, ${ }^{1}$ Jenny Yang, BS, ${ }^{1}$ Joel S. Beckett, MD, MHS, ${ }^{4}$ Cheryl Lacadie, BS, ${ }^{2}$ \\ Dustin Scheinost, PhD, ${ }^{2}$ Sarah Persing, MD, MPH, ${ }^{1}$ Elizabeth G. Zellner, MD, ${ }^{1}$ Devon Oosting, BS, ${ }^{5}$ \\ Cara Keifer, BA, ${ }^{5}$ Hannah E. Friedman, BA, ${ }^{5}$ Brent Vander Wyk, PhD, ${ }^{5}$ Roger J. Jou, MD, PhD, ${ }^{5}$ \\ Haosi Sun, BS, ${ }^{1}$ Cyril Gary, BA, ${ }^{1}$ Charles C. Duncan, MD, ${ }^{3}$ R. Todd Constable, PhD, ${ }^{2,3,6}$ \\ Kevin A. Pelphrey, PhD, ${ }^{5}$ and John A. Persing, MD ${ }^{1}$
}

1Section of Plastic and Reconstructive Surgery, ${ }^{2}$ Department of Diagnostic Radiology, and ${ }^{3}$ Department of Neurosurgery, Yale School of Medicine, New Haven, Connecticut; " ${ }^{2}$ epartment of Neurosurgery, University of California, Los Angeles, California; and ${ }^{5}$ Center for Translational Developmental Neuroscience, Child Study Center, and ${ }^{6}$ Department of Biomedical Engineering, Yale University, New Haven, Connecticut

OBJECTIVE Nonsyndromic craniosynostosis (NSC) is associated with significant learning disability later in life. Surgical reconstruction is typically performed before 1 year of age to correct the cranial vault morphology and to allow for normalized brain growth with the goal of improving cognitive function. Yet, no studies have assessed to what extent normalized brain growth is actually achieved. Recent advances in MRI have allowed for automated methods of objectively assessing subtle and pronounced brain morphological differences. The authors used one such technique, deformation-based morphometry (DBM) Jacobian mapping, to determine how previously treated adolescents with sagittal NSC (sNSC) significantly differ in brain anatomy compared with healthy matched controls up to 11.5 years after surgery.

METHODS Eight adolescent patients with SNSC, previously treated via whole-vault cranioplasty at a mean age of 7 months, and 8 age- and IQ-matched control subjects without craniosynostosis (mean age for both groups $=12.3$ years), underwent functional 3-T MRI. Statistically significant group tissue-volume differences were assessed using DBM, a whole-brain technique that estimates morphological differences between 2 groups at each voxel $(p<0.01)$. Group-wise Jacobian volume maps were generated using a spacing of $1.5 \mathrm{~mm}$ and a resolution of $1.05 \times 1.05 \times 1.05 \mathrm{~mm}^{3}$.

RESULTS There were no significant areas of volume reduction or expansion in any brain areas in adolescents with sNSC compared with controls at a significance level of $p<0.01$. At the more liberal threshold of $p<0.05$, two areas of brain expansion extending anteroposteriorly in the right temporooccipital and left frontoparietal regions appeared in patients with sNSC compared with controls.

CONCLUSIONS Compared with previous reports on untreated infants with sNSC, adolescents with sNSC in this cohort had few areas of brain dysmorphology many years after surgery. This result suggests that comprehensive cranioplasty performed at an early age offers substantial brain normalization by adolescence, but also that some effects of vault constriction may still persist after treatment. Specifically, few areas of expansion in frontoparietal and temporooccipital regions may persist. Overall, data from this small cohort support the primary goal of surgery in allowing for more normalized brain growth. Larger samples, and correlating degree of normalization with cognitive performance in NSC, are warranted.

http://thejns.org/doi/abs/10.3171/2015.7.PEDS15221

KEY WORDS magnetic resonance imaging; voxel-based morphometry; deformation-based morphometry; craniofacial; sagittal craniosynostosis

ABBREVIATIONS DBM = deformation-based morphometry; DTI = diffusion tensor imaging; fMRI = functional MRI; NSC = nonsyndromic craniosynostosis; sNSC = sagittal NSC; WISC-III = Wechsler Intelligence Scale for Children, Third Edition.

SUBMITTED April 11, 2015. ACCEPTED July 13, 2015.

INCLUDE WHEN CITING Published online December 18, 2015; DOI: 10.3171/2015.7.PEDS15221. 
$\mathrm{C}$ RANIOSYNOSTOSIS results from the premature pathological fusion of the calvarial sutures. It is an uncommon, but not rare, condition of infancy occurring in 1 in 2000 to 1 in 2500 live births. ${ }^{9,54}$ Fusion of the sutures results in abnormal calvarial and concomitant brain morphology as the tissue is forced to expand into areas where there is lack of restriction. Isolated fusion of the sagittal suture, or sagittal nonsyndromic craniosynostosis (sNSC), represents the most common form of craniosynostosis, comprising 40\%-60\% of all isolated cases, ${ }^{37}$ and results in the hallmark head shape deformity, scaphocephaly. If left untreated, the deformity progresses; ${ }^{28}$ therefore, surgical release of the vault has often been performed in the first year of life to allow for both normalized head shape, as well as more normalized brain growth.

Currently, recent reports show that as many as $50 \%$ of children with sNSC grow to have some form of cognitive disability, despite having IQs in the normal range. ${ }^{5,40,64}$ The most common issues reported in children with sNSC include those involving attention and behavior (executive function), language, and visuospatial processing. ${ }^{36,40}$ Therefore, an impetus for early intervention is to hopefully improve or attenuate these perceived cognitive deficits, with the assumption that surgery may allow for a more normalized brain growth pattern. ${ }^{15,16,42,52,55,62}$

Yet, to date, no studies have been conducted to assess whether this primary endpoint of surgery is reached in older children with sNSC, i.e., whether the vault remodeling in infancy does, in fact, ultimately lead to a normal brain morphology. We aimed to address this question using a novel advanced MRI technique, deformation-based morphometry (DBM) Jacobian determinant mapping, that allowed accurate quantification of where and how the brains of adolescents with sNSC, up to 11.5 years after whole-vault reconstruction, differ in anatomy in relation to a group of age- and IQ-matched healthy adolescent controls.

\section{Methods \\ Study Populations}

This was a prospective cohort study performed with approval from the Yale School of Medicine Human Investigations Committee. We studied 8 adolescents (mean age 12.3 years) with sNSC (treated by Drs. Persing and Duncan) via whole-vault cranioplasty at Yale-New Haven Hospital and 8 control children (mean age 12.3 years) without craniosynostosis. Whole-vault cranioplasty was defined as remodeling of the anterior and posterior skull and the parietal region, as described previously by Persing et al. ${ }^{50}$ A retrospective chart review of patients with isolated sagittal synostosis between the ages of 11 and 14 years was performed. Operative summaries were reviewed to confirm the diagnosis of isolated sagittal synostosis. $\mathrm{Pa}-$ tients meeting inclusion/exclusion criteria after chart review were contacted to participate and all children still residing within acceptable travel distance to Yale-New Haven Hospital agreed to enroll. Control children were selected from an existing Yale Child Study Center control database based on matching criteria. Exclusion criteria required that children with $\mathrm{sNSC}$ did not exhibit signs of syndromic craniosynostosis (specifically extracranial skeletal manifestations), and both groups of children were without cranial prostheses, mental retardation, known neurological or psychiatric disorders, history of traumatic head injury, or intracranial hemorrhage. As illustrated in Table 1, the two groups were group-matched by age, sex, race, and handedness, as well as by performance IQ and verbal IQ as measured by the Wechsler Intelligence Scale for Children, Third Edition (WISC-III). ${ }^{66}$ Matching criteria were selected based on consultation from academic child psychiatrists and neuroimaging experts at the Yale Child Study Center and the departments of neurosurgery and diagnostic radiology to ensure limitation of confounders that could affect imaging results.

\section{Image Acquisition and Registration}

All of the MR images were obtained on a single 3-T Siemens Tim Trio MRI system with a 32-channel polarized head coil. Images were obtained using a sagittal, 3D, integrated parallel acquisition technique with TR 1900 msec, TE $2.96 \mathrm{msec}$, flip angle $9^{\circ}$, matrix size $256 \times 256$, slice thickness $1 \mathrm{~mm}$, and 160 contiguous slices.

To facilitate better image registration, we used the FMRIB Software Library's brain extraction tool to remove the skull and meninges from each subject's 3D anatomical image. Any remaining skull or meninges were removed manually. Five nonlinear registrations were computed within the Yale BioImageSuite software package ${ }^{48}$ between the individual brain extracted 3D anatomical image and a commonly used 3D reference image (the Colin Brain, Holmes et al., 1998 ${ }^{29}$ ) in Montreal Neurological Institute space (Evans et al., 199321) using the intensity-only component of the method reported in Papademetris and colleagues. ${ }^{47}$ The first registration was performed with a control spacing of $15 \mathrm{~mm}$. It was then used as the starting point for the second registration, which was performed with a control spacing of $10 \mathrm{~mm}$. The 3 subsequent registrations each used the previous registration as the starting point and continued to get more refined with a control spacing of $5 \mathrm{~mm}, 2 \mathrm{~mm}$, and finally $1.5 \mathrm{~mm}$. All subjects' registrations were visually inspected to ensure accuracy.

\section{Deformation-Based Morphometry and Jacobian Mapping}

Jacobians, or Jacobian determinants, are measures of

TABLE 1. Characteristics of patients with sNSC and controls

\begin{tabular}{lccc}
\hline \multicolumn{1}{c}{ Characteristic } & $\begin{array}{c}\text { Children w/ } \\
\text { Corrected sNSC }\end{array}$ & $\begin{array}{c}\text { Control } \\
\text { Children }\end{array}$ & $\begin{array}{c}\mathrm{p} \\
\text { Value }\end{array}$ \\
\hline No. of patients & 8 & 8 & \\
\hline Mean age in yrs (SD) & $12.3(1.8)$ & $12.3(1.6)$ & NS \\
\hline Sex (M/F) & $(6 / 2)$ & $(7 / 1)$ & NS \\
\hline Race (W/AA) & $(7 / 1)$ & $(7 / 1)$ & NS \\
\hline Handedness (rt) & 8 & 8 & NS \\
\hline Mean age at op in mos (SD) & $7(2)$ & & \\
\hline WISC-III Testing (SD) & & & \\
\hline \multicolumn{1}{c}{ Mean performance IQ } & $111(15)$ & $115(10)$ & NS \\
\hline Mean verbal IQ & $100(16)$ & $120(16)$ & NS \\
\hline AA
\end{tabular}

$A A=$ African American; $N S=$ not significant; $W=$ white. 
regional tissue volume change when an individual's brain is warped to common space during nonlinear registration. ${ }^{3}$ Jacobians are partial first-order derivatives of a vectorvalued function, such as that used to warp brains onto a common template in MRI. ${ }^{13,27}$ Jacobian values indicate how much expanding or contracting a given subject's brain undergoes during alignment, and thus can be used to quantify the anatomical variability between groups. Jacobian values can be produced for any given brain voxel in the reference coordinate system $(\mathrm{x}, \mathrm{y}, \mathrm{z})$ to describe the pointwise volume change induced by the transformation for a subject (Fig. 1).

Jacobian values greater than 1 indicate tissue contraction, values less than 1 indicate tissue expansion, values of 0 indicate folding, and infinite values indicate tearing. The production of these determinants allows one to generate parametric maps of local tissue anatomical variability-contraction and expansion-for each subject. The individual maps generated in a patient group can thus be compared with the individual maps in a control group. This comparison reveals whether there are brain areas that require more expansion or contraction during registration, which in turn informs us of the magnitude of differences in gross morphology anywhere in the brain in one group relative to the other. ${ }^{14}$ This provides an objective, automated analysis with high regional sensitivity to anatomical differences between two groups throughout the entire brain (deep and superficial structures) and gives an excellent, quantitative assessment of both subtle and pronounced morphological differences. ${ }^{23,56,63,65}$

\section{Jacobian Analysis}

The nonlinear registrations computed within BioImageSuite were used to produce Jacobian maps of local expansion/contraction where each voxel has a value representing the local volume change required to map that voxel of an individual participant's brain to the reference Montreal Neurological Institute brain. The Jacobian maps were generated using a spacing of $1.5 \mathrm{~mm}$ and a resolution of $1.05 \times 1.05 \times 1.05 \mathrm{~mm}^{3}$. This process was completed for all participants in both sNSC and control groups using a spacing of $1.5 \mathrm{~mm}$ and resolution of $1.05 \mathrm{~mm}^{3}$ (Fig. 2). Average maps were then generated using the individual Jacobian maps for each group (Fig. 3). Finally, the sNSC and control average Jacobian maps were compared against each other. To measure the smoothness of the data, the Analysis of Functional NeuroImages' 3dFWHmx program was used on the residuals of the t-tests and found a smoothness of $6.57 \times 7.22 \times 6.87 \mathrm{~mm}$. This smoothness was imputed into AFNI's AlphaSim program to determine the proper cluster for multiple comparison correc-

$$
J(x, y, z)=\mid \begin{array}{ccc}
1+\partial \mathrm{u}_{x} / \partial \mathrm{x} & \partial \mathrm{u}_{\mathrm{x}} / \partial \mathrm{y} & \partial \mathrm{u}_{\mathrm{x}} / \partial \mathrm{z} \\
\partial \mathrm{u}_{\mathrm{y}} / \partial \mathrm{x} & 1+\partial \mathrm{u}_{\mathrm{y}} / \partial \mathrm{y} & \partial \mathrm{u}_{\mathrm{y}} / \partial \mathrm{z} \\
\partial \mathrm{u}_{\mathrm{z}} / \partial \mathrm{x} & \partial \mathrm{u}_{\mathrm{z}} / \partial \mathrm{y} & 1+\partial \mathrm{u}_{\mathrm{z}} / \partial \mathrm{z}
\end{array}
$$

FIG. 1. Jacobian values $(\mathrm{J})$ can be produced for any given brain voxel in the reference coordinate system $(x, y, z)$ to describe the point-wise volume change induced by the transformation for a subject. tion, which resulted in a cluster of $1775 \mathrm{~mm}^{3}$ at a significance threshold of $\mathrm{p}<0.01$ and $7425 \mathrm{~mm}^{3}$ at a significance threshold of $\mathrm{p}<0.05$. When comparing the sNSC and control groups, voxels that had a t value greater than $2.974(\mathrm{p}$ $<0.01)$ and were part of a spatially continuous cluster size of $1775 \mathrm{~mm}^{3}$ were considered to be significantly different. Also included were the more liberal exploratory data in which voxels had a threshold of a $t$ value greater than $2.144(\mathrm{p}<0.05)$ and were part of a spatially contiguous cluster size of $7425 \mathrm{~mm}^{3}$.

\section{Results}

As illustrated in Fig. 4, direct statistical comparison of Jacobian parametric maps between the two groups revealed no areas of pronounced or localized group brain differences at the predetermined threshold of $\mathrm{p}<0.01$; specifically, there were no significant areas of volume reduction or expansion in any brain areas in adolescents with sNSC compared with controls at the $\mathrm{p}<0.01$ threshold. Only at the more liberal statistical threshold of $p<0.05$ did areas of localized brain expansion appear in sNSC compared with controls. These areas of brain expansion extended anteroposteriorly in the right temporooccipital and left frontoparietal regions (Brodmann areas 41, 39, 22, and 19 , and $6,4,3,2$, and 1 , respectively).

\section{Discussion}

A critical question in the treatment of sNSC is that of cognitive function. The most recent data strongly suggest that infants with sNSC can be identified to have significantly impaired cognitive, motor, and/or language development prior to treatment. $70-12,35,38,57$ Starr and colleagues recently found infants with sNSC have up to a 2.0 increased odds of delayed mental, psychomotor, and/or language development compared with their healthy, typically developing counterparts. ${ }^{58}$ Even after treatment, up to $50 \%$ of adolescents with sNSC continue to experience problems in attention and behavior, language, and visuospatial processing, despite having a normal IQ. ${ }^{5,40,57}$ The goal of early surgery to provide excellent cosmetic outcomes through vault reconstruction has been well established..$^{17,25,41,43,46}$ However, the question "does surgery assist in normalized brain development and improved cognitive performance later in life?" is one of great importance.

Recent studies have offered evidence of the value of early vault release in preventing or abating cognitive deficit later in life. A large, well-powered, and appropriately designed study using the most up-to-date neurocognitive assessments revealed that earlier vault release, performed before 6 months of age, is associated with improved intellectual and developmental quotient outcomes later in life. ${ }^{49}$ Furthermore, another recent study demonstrated that a more comprehensive remodeling technique confers a significantly better intellectual and developmental outcome compared with the widely employed modified strip craniectomy. ${ }^{26}$ Modified strip craniectomy has gained popularity recently as it is associated with less operative time, less blood loss, and can be performed at an earlier age, $, 5,8,34$ but the aforementioned findings indicate that long-term outcomes on functional performance may not be equiva- 


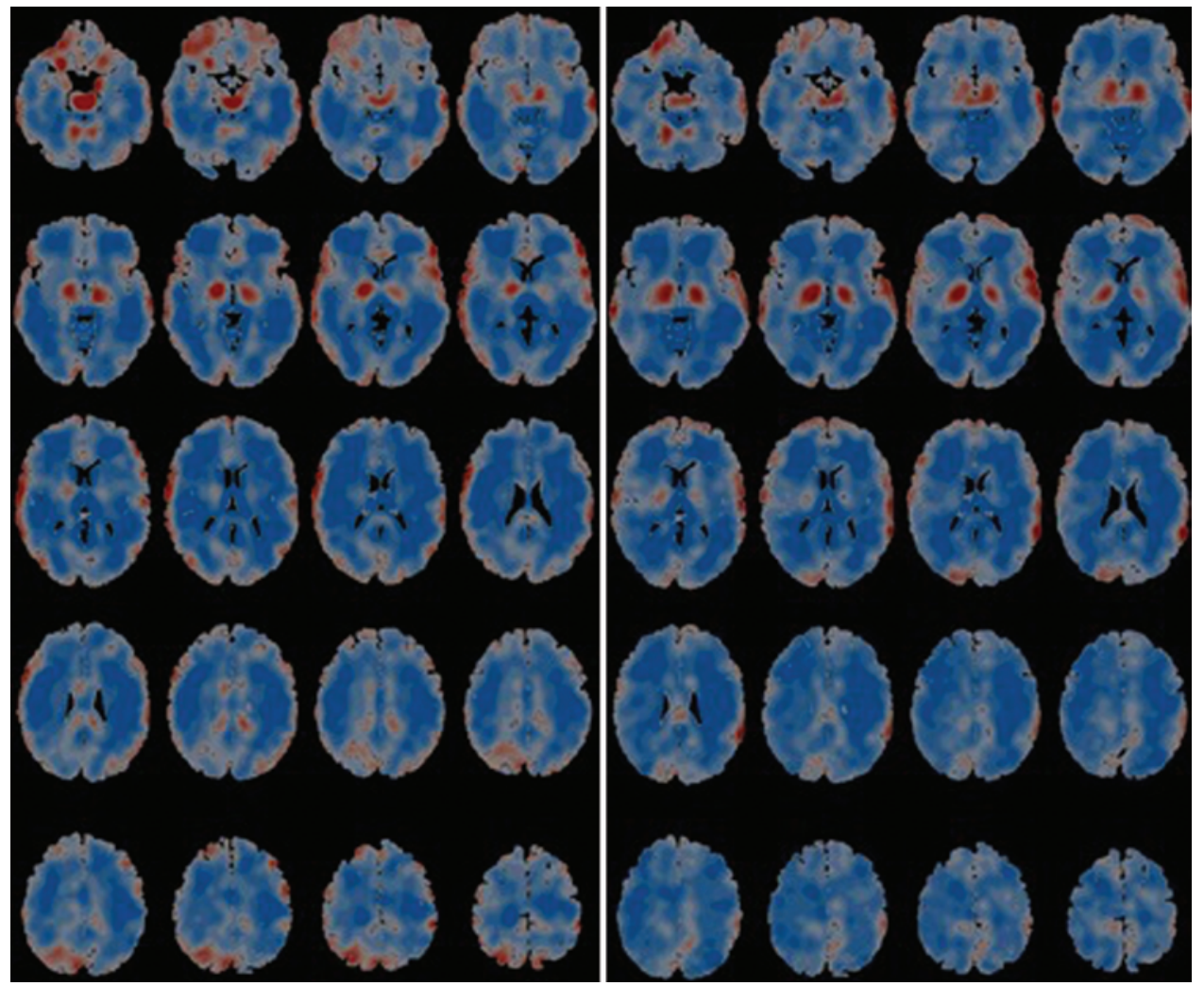

FIG. 2. Examples of individual Jacobian maps generated for both a control (left) and an SNSC (right) subject. Blue represents areas of brain volume contraction. Red represents areas of brain volume expansion. The spacing is $1.5 \mathrm{~mm}$ and the resolution is $1.05 \mathrm{~mm}^{3}$. Figure is available in color online only.

lent. While further study is needed, these studies appear to align and indicate that maximum neurocognitive benefit is achieved by early comprehensive vault remodeling.

The coupling of advanced functional MRI (fMRI) and diffusion tensor imaging (DTI) provided novel insight into understanding the aforementioned cognitive deficit in these children. Until recently, the few existing basic clinical MRI studies have failed to identify any overt and consistent brain structure malformations in sNSC. ${ }^{20,32} \mathrm{Re}-$ cently, fMRI demonstrated that children with sNSC have altered functional brain connectivity in regions responsible for the cognitive functions observed to be delayed in the sNSC population. ${ }^{6}$ Specifically, the prefrontal cortex, which is responsible for executive function, and the left lateral parietal cortex, which is responsible for language and visuospatial processing, have significantly altered connectivity in children with SNSC compared with controls. Significant connectivity differences involving the default mode network, which is the primary network at rest but is also needed to perform well in school-like tasks, ${ }^{24}$ are also altered in children with SNSC as compared with controls. Finally, DTI revealed trends toward altered white matter microstructure in children with sNSC. Taken together, these results point to a more insidious process that results not in overt brain malformation in NSC, but rather more subtle functional and microstructural disorganization that may, in part or whole, underlie the cognitive disabilities so commonly observed in these children.
An emerging goal, then, of early surgical intervention is to abate or improve the cognitive dysfunction in these children by hopefully allowing for more normalized brain growth after vault constriction release, and attenuate whatever insidious process may be taking place. . $^{15,16,42,52,55,62}$ However, no studies have evaluated whether this very basic assumption and goal of surgery is achieved; that is, whether the brains of children with sNSC become more normalized in morphology after surgery.

This study, the first (to our knowledge) to evaluate brain normalization in previously treated adolescents with sNSC, indicates that substantial brain normalization is achieved when early comprehensive surgical intervention is performed in infancy. Although there have been many functional, cosmetic, and cognitive outcome reports on this condition, 5,6,25,40,41,64 none addressed the basic question of whether a primary goal of surgery-to allow for more normalized brain growth and development-is actually achieved. Brain dysmorphology in infants with sNSC who have not undergone surgery has been well documented. Before surgery, infants with sNSC demonstrate significant lengthening of the brain anteroposteriorly, lengthening between the posterior horns of the lateral ventricles and occipital poles, mediolateral expansion of structures in the anterior frontal region, and mediolateral constriction notable on the left side. ${ }^{2}$ Aldridge and colleagues examined brain morphological changes following surgery in this same cohort of infant subjects, studying the ratios of linear 


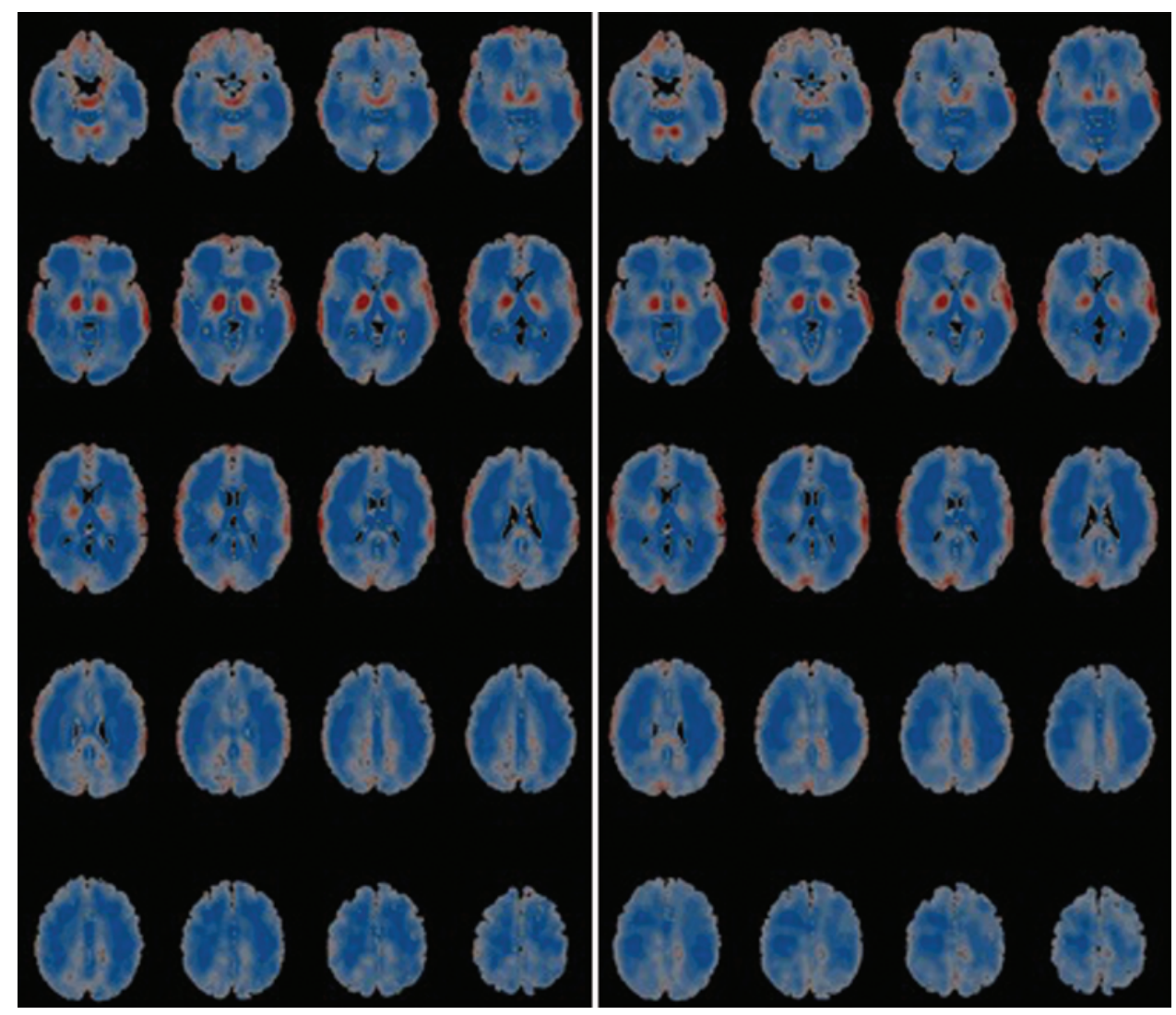

FIG. 3. Average Jacobian group maps generated for controls (left) and those with sNSC (right). Blue represents areas of brain volume contraction. Red represents areas of brain volume expansion. The spacing is $1.5 \mathrm{~mm}$ and the resolution is $1.05 \mathrm{~mm}^{3}$. Areas of localized brain volume expansion and contraction are qualitatively similar for both groups. Figure is available in color online only.

distances between 32 identifiable cortical and subcortical brain structures. ${ }^{1}$ As expected, ratios of these distances differed significantly in untreated infants with sNSC as compared with controls. Following surgery, the brains of the infants with sNSC assumed a much more normal globular shape, but ratios of distances between structures were still deviated from normal, and overall brain shape reorganized to a morphology somewhere between normal and where it was preoperatively. Thus, Aldridge and colleagues helped to answer the very important question of whether surgery impacts the trajectory of brain growth, revealing that certain aspects of brain morphology soon after intervention did, in some way, revert to a more normalized pattern. However, limitations of the study were that analysis was only performed at 1 year after surgery (postsurgery age range at the time of assessment was 1.4-2.4 years), and it was not based on objective, wholebrain assessment to determine morphological differences throughout the entire brain. These factors are significant because brain volume doubles by 6 months, triples by 2.5 years, continues to grow rapidly until age 3 , and then begins to decelerate until age 6 , when the cranial vault reaches $90 \%$ of its adult size. ${ }^{33,52}$ The brain also continues to grow steadily in size across childhood, and experiences another developmental spurt in adolescence, not reaching its full adult weight until the late teens or early 20s. ${ }^{33,51,59}$ During this time, synaptogenesis, pruning, and myelination are fervently active and contribute to the overall shape, size, and connectivity that is reached.$^{61}$ This current study, which relies on more sensitive, objective, and whole brain analysis and examines adolescent outcomes of infant surgical patients (with a mean age of 12.3 years), is more appropriate for quantifying true final morphological differences because the brains of our subjects have had sufficiently more time to grow and potentially normalize (11-11.5 years after surgery).

Our findings demonstrate that the brains of these patients, at least in this small cohort, do, in fact, appear to continue along a more normalized trajectory following surgery, to the point that they reach substantial normalization by early adolescence. Compared with the extensive morphological differences observed in the brains of infants with SNSC, ${ }^{1,2}$ our adolescent cohort showed few areas of significant differences in brain morphology. Specifically, there were no areas of significant brain expansion or contraction between those with sNSC and controls at the predetermined threshold of $p<0.01$. The use of the more exploratory liberal threshold of $p<0.05$ demonstrated two areas of brain expansion extending anteroposteriorly in the right temporooccipital and left frontoparietal regions in adolescents with sNSC compared with controls. Conceivably, these two areas of brain expansion represent residual 


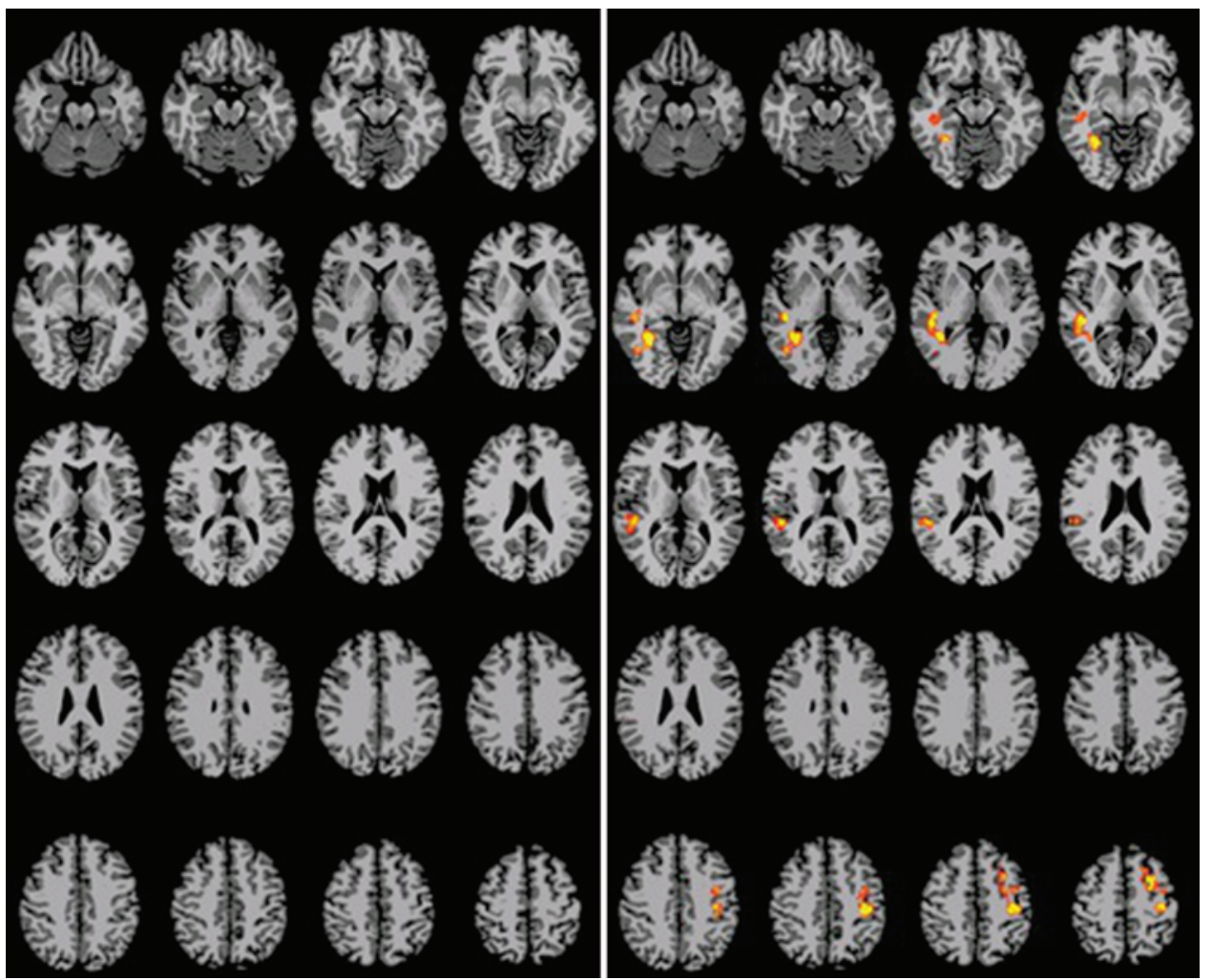

FIG. 4. Voxel-wise Jacobian comparison of average maps between sNSC and controls (left) reveals no pronounced or localized differences in brain morphology (localized brain volume contraction or expansion) between sNSC adolescents and controls at $p<$ 0.01 , but two areas of brain expansion extending anteroposteriorly in the right temporal (Brodmann areas 41,39, 22, and 19) and left frontoparietal (Brodmann areas 6, 4, 3, 2, and 1) regions at $p<0.05$ (right). Blue indicates areas of brain constriction in sNSC versus controls, red indicates areas of brain expansion in SNSC versus controls, and gray indicates no difference. The spacing is $1.5 \mathrm{~mm}$ and the resolution is $1.05 \mathrm{~mm}^{3}$. Figure is available in color online only.

areas of the frontoparietal and temporooccipital brain expansion noted in infants with sNSC before treatment. ${ }^{1,2}$ This result provides evidence that while the majority of the brain might achieve normalized morphology by adolescence (i.e., absence of mediolateral contraction, extensive diffuse anteroposterior expansion, and dysmorphology between deep brain structures), some regions may not. The implications of these changes on cognition and long-term outcomes are yet to be determined. Small changes in functional structural organization over time can lead to cognitive deficit. Therefore, allowing for a more normalized morphology or neural organization through surgery may be what drives potentially better cognitive outcomes. . $^{44,45}$ This is illustrated again by higher intelligence and developmental status through earlier and more comprehensive skull remodeling. ${ }^{26,49}$ There is mounting evidence that significant deviations in locoregional brain shape are associated with neurocognitive and executive function disorders, including attention-deficit hyperactivity disorder and autism. ${ }^{19,22,65}$ It is also known that the two brain regions found to be dysmorphic in our cohort are responsible for language and visuospatial as well as verbal and spatial processing, the functions most commonly reported to be impaired in children with sNSC..$^{18,30,53,60}$ Because of this, it may become even more imperative that early comprehen- sive brain shape normalization be achieved, and the lasting morphological effects be thoroughly studied.

Moving forward, larger, prospective longitudinal samples of subjects, coupled with extensive neurocognitive testing, are needed. We know from neurodevelopmental studies that there exist critical periods in early brain development, and that prolonged disruption of functional organization during these periods can lead to permanent deficits. ${ }^{31,39}$ As discussed above, constriction of the vault appears to play some role in creating deficit during this critical period in infants with sNSC, as revealed not only by subtle cognitive deficits later in life in spite of surgery, but also by better cognitive outcomes when earlier $(<6$ months) and more immediately corrective (i.e., wholevault) techniques are used to intervene. These data provide hope that even if there is a primary neurological deficit in sNSC, it can be improved with surgery. This current study demonstrates that, compared with the numerous brain irregularities that are observed in infancy, there is substantially normalized brain growth morphology by adolescence (when early surgical intervention occurs around the age of 7 months). Yet, consistent with the fact that cognitive deficits persist in spite of surgery, we also found that some brain shape irregularities do persist in spite of treatment. This highlights again how lasting effects can 
occur when an insult happens during a critical time in early development. Our study does not address correlation to neurocognitive data, and it relies on a small sample size. There may exist subpopulations of patients with sNSC with more pronounced morphological differences. If so, it will be important to reveal how the degree of normalization achieved through surgery relates to baseline indices of head shape deformity and to cognitive outcomes. It will also be important to compare these adolescent DBM data to those obtained from infants prior to treatment and, going a step further, evaluate what effect the different forms of treatment have on brain shape normalization in patients with sNSC. However, given the paucity of data on this important clinical topic and the novelty of our results, we believe our study provides encouraging data for the continued investigation of the effects of surgery on brain structure and function through MR analytics. We now show, for the first time, that the basic and important goal of allowing for more normalized brain growth appears to be, at least in part, achieved through surgery.

\section{Conclusions}

Morphometric analysis, using automated and objective MR DBM, demonstrates that children with sNSC achieve substantial brain normalization following surgery compared with the numerous brain shape irregularities reported in previous studies on untreated infants with SNSC. Allowing for brain normalization to positively impact cognitive function is a primary goal of calvarial release. Thus, these results support early intervention through cranioplasty to allow for more normalized brain growth in children with sNSC.

\section{Acknowledgements}

This work was funded by an NIH CTSA-TL1 grant; the American Society of Maxillofacial Surgeons; the Doris Duke Charitable Foundation Clinical Scholars Fellowship; and a Harris Professorship to Kevin Pelphrey.

\section{References}

1. Aldridge K, Kane AA, Marsh JL, Yan P, Govier D, Richtsmeier JT: Relationship of brain and skull in pre- and postoperative sagittal synostosis. J Anat 206:373-385, 2005

2. Aldridge K, Marsh JL, Govier D, Richtsmeier JT: Central nervous system phenotypes in craniosynostosis. J Anat 201:31-39, 2002

3. Ashburner J: Computational anatomy with the SPM software. Magn Reson Imaging 27:1163-1174, 2009

4. Barone CM, Jimenez DF: Endoscopic craniectomy for early correction of craniosynostosis. Plast Reconstr Surg 104:1965-1975, 1999

5. Becker DB, Petersen JD, Kane AA, Cradock MM, Pilgram TK, Marsh JL: Speech, cognitive, and behavioral outcomes in nonsyndromic craniosynostosis. Plast Reconstr Surg 116:400-407, 2005

6. Beckett JS, Brooks ED, Lacadie C, Vander Wyk B, Jou RJ, Steinbacher DM, et al: Altered brain connectivity in sagittal craniosynostosis. J Neurosurg Pediatr 13:690-698, 2014

7. Bellew M, Chumas P, Mueller R, Liddington M, Russell J: Pre- and postoperative developmental attainment in sagittal synostosis. Arch Dis Child 90:346-350, 2005

8. Chan JW, Stewart CL, Stalder MW, St Hilaire H, McBride
L, Moses MH: Endoscope-assisted versus open repair of craniosynostosis: a comparison of perioperative cost and risk. J Craniofac Surg 24:170-174, 2013

9. Cohen MM Jr: Epidemiology of craniosynostosis, in Cohen MM Jr, MacLean RE (eds): Craniosynostosis: Diagnosis, Evaluation, and Management. New York: Oxford University Press, 2000, pp 112-118

10. Cohen SR, Cho DC, Nichols SL, Simms C, Cross KP, Burstein FD: American society of maxillofacial surgeons outcome study: preoperative and postoperative neurodevelopmental findings in single-suture craniosynostosis. Plast Reconstr Surg 114:841-849, 2004

11. Da Costa AC, Anderson VA, Holmes AD, Lo P, Wray AC, Chong DK, et al: Longitudinal study of the neurodevelopmental characteristics of treated and untreated nonsyndromic craniosynostosis in infancy. Childs Nerv Syst 29:985-995, 2013

12. Da Costa AC, Anderson VA, Savarirayan R, Wrennall JA, Chong DK, Holmes AD, et al: Neurodevelopmental functioning of infants with untreated single-suture craniosynostosis during early infancy. Childs Nerv Syst 28:869-877, 2012

13. Dacorogna B, Jürgen M: On a partial differential equation involving the Jacobian determinant. Ann Inst Henri Poincaré, $7: 1-26,1990$

14. Davatzikos C, Vaillant M, Resnick SM, Prince JL, Letovsky S, Bryan RN: A computerized approach for morphological analysis of the corpus callosum. J Comput Assist Tomogr 20:88-97, 1996

15. David LR, Genecov DG, Camastra AA, Wilson JA, Argenta LC: Positron emission tomography studies confirm the need for early surgical intervention in patients with single-suture craniosynostosis. J Craniofac Surg 10:38-42, 1999

16. David LR, Wilson JA, Watson NE, Argenta LC: Cerebral perfusion defects secondary to simple craniosynostosis. J Craniofac Surg 7:177-185, 1996

17. Di Rocco C: Nonsyndromic craniosynostosis, in Sindou M (ed): Practical Handbook of Neurosurgery. Vienna: Springer, 2009, pp 561-584

18. Dupont P, Orban GA, Vogels R, Bormans G, Nuyts J, Schiepers C, et al: Different perceptual tasks performed with the same visual stimulus attribute activate different regions of the human brain: a positron emission tomography study. Proc Natl Acad Sci U S A 90:10927-10931, 1993

19. Ecker C, Suckling J, Deoni SC, Lombardo MV, Bullmore ET, Baron-Cohen S, et al: Brain anatomy and its relationship to behavior in adults with autism spectrum disorder: a multicenter magnetic resonance imaging study. Arch Gen Psychiatry 69:195-209, 2012

20. Engel M, Hoffmann J, Mühling J, Castrillón-Oberndorfer G, Seeberger R, Freudlsperger C: Magnetic resonance imaging in isolated sagittal synostosis. J Craniofac Surg 23:e366e369, 2012

21. Evans AC, Collins DL, Mills SR, Brown ED, Kelly RL, Peters TM: 3D statistical neuroanatomical models from 305 MRI volumes, in Proceedings of the IEEE Nuclear Science Symposium and Medical Imaging Conference. New York: IEEE, 1993, pp 1813-1817

22. Frodl T, Skokauskas N: Meta-analysis of structural MRI studies in children and adults with attention deficit hyperactivity disorder indicates treatment effects. Acta Psychiatr Scand 125:114-126, 2012

23. Gaser C, Volz HP, Kiebel S, Riehemann S, Sauer H: Detecting structural changes in whole brain based on nonlinear deformations-application to schizophrenia research. Neuroimage 10:107-113, 1999

24. Hampson M, Driesen NR, Skudlarski P, Gore JC, Constable RT: Brain connectivity related to working memory performance. J Neurosci 26:13338-13343, 2006

25. Hankinson TC, Fontana EJ, Anderson RC, Feldstein NA: 
Surgical treatment of single-suture craniosynostosis: an argument for quantitative methods to evaluate cosmetic outcomes. J Neurosurg Pediatr 6:193-197, 2010

26. Hashim PW, Patel A, Yang JF, Travieso R, Terner J, Losee JE, et al: The effects of whole-vault cranioplasty versus strip craniectomy on long-term neuropsychological outcomes in sagittal craniosynostosis. Plast Reconstr Surg 134:491-501, 2014

27. Hazewinkel M (ed): Encyclopaedia of Mathematics, Supplement III. Dordrecht: Kluwer, 2001

28. Heller JB, Heller MM, Knoll B, Gabbay JS, Duncan C, Persing JA: Intracranial volume and cephalic index outcomes for total calvarial reconstruction among nonsyndromic sagittal synostosis patients. Plast Reconstr Surg 121:187-195, 2008

29. Holmes CJ, Hoge R, Collins L, Woods R, Toga AW, Evans AC: Enhancement of MR images using registration for signal averaging. J Comput Assist Tomogr 22:324-333, 1998

30. Horwitz B, Rumsey JM, Donohue BC: Functional connectivity of the angular gyrus in normal reading and dyslexia. Proc Natl Acad Sci U S A 95:8939-8944, 1998

31. Hubel DH, Wiesel TN: The period of susceptibility to the physiological effects of unilateral eye closure in kittens. J Physiol 206:419-436, 1970

32. Hukki A, Koljonen V, Karppinen A, Valanne L, Leikola J: Brain anomalies in 121 children with non-syndromic single suture craniosynostosis by MR imaging. Eur J Paediatr Neurol 16:671-675, 2012

33. Iwasaki N, Hamano K, Okada Y, Horigome Y, Nakayama J, Takeya T, et al: Volumetric quantification of brain development using MRI. Neuroradiology 39:841-846, 1997

34. Jimenez DF, Barone CM: Endoscopic craniectomy for early surgical correction of sagittal craniosynostosis. J Neurosurg 88:77-81, 1998

35. Kapp-Simon KA, Leroux B, Cunningham M, Speltz ML: Multisite study of infants with single-suture craniosynostosis: preliminary report of presurgery development. Cleft Palate Craniofac J 42:377-384, 2005

36. Kapp-Simon KA, Speltz ML, Cunningham ML, Patel PK, Tomita T: Neurodevelopment of children with single suture craniosynostosis: a review. Childs Nerv Syst 23:269-281, 2007

37. Kolar JC: An epidemiological study of nonsyndromal craniosynostoses. J Craniofac Surg 22:47-49, 2011

38. Korpilahti P, Saarinen P, Hukki J: Deficient language acquisition in children with single suture craniosynostosis and deformational posterior plagiocephaly. Childs Nerv Syst 28:419-425, 2012

39. LeVay S, Wiesel TN, Hubel DH: The development of ocular dominance columns in normal and visually deprived monkeys. J Comp Neurol 191:1-51, 1980

40. Magge S, Westerveld M, Pruzinsky T, Persing J: Long-term neuropsychological effects of sagittal craniosynostosis on child development. J Craniofac Surg 13:99-104, 2002

41. Marcus JR, Stokes TH, Mukundan S, Forrest CR: Quantitative and qualitative assessment of morphology in sagittal synostosis: mid-sagittal vector analysis. J Craniofac Surg 17:680-686, 2006

42. Martini M, Röhrig A, Wenghoefer M, Schindler E, MessingJünger AM: Cerebral oxygenation and hemodynamic measurements during craniosynostosis surgery with near-infrared spectroscopy. Childs Nerv Syst 30:1367-1374, 2014

43. Maugans TA, McComb JG, Levy ML: Surgical management of sagittal synostosis: a comparative analysis of strip craniectomy and calvarial vault remodeling. Pediatr Neurosurg 27:137-148, 1997

44. Morton JB, Munakata Y: What's the difference? Contrasting modular and neural network approaches to understanding developmental variability. J Dev Behav Pediatr 26:128-139, 2005
45. Munakata Y, Casey BJ, Diamond A: Developmental cognitive neuroscience: progress and potential. Trends Cogn Sci 8:122-128, 2004

46. Panchal J, Marsh JL, Park TS, Kaufman B, Pilgram T, Huang SH: Sagittal craniosynostosis outcome assessment for two methods and timings of intervention. Plast Reconstr Surg 103:1574-1584, 1999

47. Papademetris X, Jackowski AP, Schultz RT, Staib LH, Duncan JS: Integrated intensity and point-feature nonrigid registration. Med Image Comput Comput Assist Interv 3216:763-770, 2001

48. Papademetris X, Jackowski MP, Rajeevan N, DiStasio M, Okuda H, Constable RT, et al: BioImage Suite: an integrated medical image analysis suite: an update. Insight J 2006:209, 2006

49. Patel A, Yang JF, Hashim PW, Travieso R, Terner J, Mayes LC, et al: The impact of age at surgery on long-term neuropsychological outcomes in sagittal craniosynostosis. Plast Reconstr Surg 134:608e-617e, 2014

50. Persing JA, Jane JA, Edgerton MT: Surgical treatment of craniosynostosis, in Persing JA, Edgerton MT, Jane JA (ed): Scientific Foundations and Surgical Treatment of Craniosynostosis. Baltimore: Williams \& Wilkins, 1989, pp117-238

51. Reiss AL, Abrams MT, Singer HS, Ross JL, Denckla MB: Brain development, gender and IQ in children. A volumetric imaging study. Brain 119:1763-1774, 1996

52. Richtsmeier JT, Aldridge K, DeLeon VB, Panchal J, Kane AA, Marsh JL, et al: Phenotypic integration of neurocranium and brain. J Exp Zoolog B Mol Dev Evol 306:360-378, 2006

53. Seghier ML: The angular gyrus: multiple functions and multiple subdivisions. Neuroscientist 19:43-61, 2013

54. Selber J, Reid RR, Chike-Obi CJ, Sutton LN, Zackai EH, McDonald-McGinn D, et al: The changing epidemiologic spectrum of single-suture synostoses. Plast Reconstr Surg 122:527-533, 2008

55. Sen A, Dougal P, Padhy AK, Bhattacharya A, Kumar R, Bal C, et al: Technetium-99m-HMPAO SPECT cerebral blood flow study in children with craniosynostosis. J Nucl Med 36:394-398, 1995

56. Shen D, Liu D, Liu H, Clasen L, Giedd J, Davatzikos C: Automated morphometric study of brain variation in XXY males. Neuroimage 23:648-653, 2004

57. Speltz ML, Kapp-Simon KA, Cunningham M, Marsh J, Dawson G: Single-suture craniosynostosis: a review of neurobehavioral research and theory. J Pediatr Psychol 29:651-668, 2004

58. Starr JR, Collett BR, Gaither R, Kapp-Simon KA, Cradock MM, Cunningham ML, et al: Multicenter study of neurodevelopment in 3-year-old children with and without single-suture craniosynostosis. Arch Pediatr Adolesc Med 166:536-542, 2012

59. Stiles J, Jernigan TL: The basics of brain development. Neuropsychol Rev 20:327-348, 2010

60. Tanaka S, Honda M, Sadato N: Modality-specific cognitive function of medial and lateral human Brodmann area 6. J Neurosci 25:496-501, 2005

61. Tau GZ, Peterson BS: Normal development of brain circuits. Neuropsychopharmacology 35:147-168, 2010

62. Uemura T, Noda K, Hayashi T, Sato K: [Evaluation of craniosynostosis surgery: Technetium-99-m-HMPAO SPECT cerebral blood flow study in children with craniosynostosis.] Nippon Keisei Geka Gakkai Kaishi 18:489-496, 1998 (Jpn)

63. Villain N, Landeau B, Groussard M, Mevel K, Fouquet M, Dayan J, et al: A simple way to improve anatomical mapping of functional brain imaging. J Neuroimaging 20:324-333, 2010

64. Virtanen R, Korhonen T, Fagerholm J, Viljanto J: Neurocog- 
nitive sequelae of scaphocephaly. Pediatrics 103:791-795, 1999

65. Wang J, Jiang T, Cao Q, Wang Y: Characterizing anatomic differences in boys with attention-deficit/hyperactivity disorder with the use of deformation-based morphometry. AJNR Am J Neuroradiol 28:543-547, 2007

66. Wechsler D: WISC-III: Wechsler Intelligence Scale for Children, ed 3. San Antonio, TX: Psychological Corporation, 1991

\section{Disclosures}

Dr. Jou has received support for nonstudy-related clinical or research effort from Hoffmann-La Roche Limited and Curemark LLC.

\section{Author Contributions}

Conception and design: J Persing, Brooks, Beckett, Vander Wyk, Jou, Duncan, Constable, Pelphrey. Acquisition of data: Brooks, Beckett, Oosting, Keifer, Friedman. Analysis and interpretation of data: Brooks, Yang, Lacadie, Scheinost, S Persing, Zellner, Sun, Gary, Pelphrey. Drafting the article: Brooks. Critically revising the article: J Persing, Yang, Beckett, Lacadie, Scheinost, S Persing, Zellner, Oosting, Keifer, Friedman, Vander Wyk, Jou, Sun, Gary, Duncan, Constable, Pelphrey. Reviewed submitted version of manuscript: all authors. Statistical analysis: Brooks, Scheinost.

\section{Correspondence}

John A. Persing, Section of Plastic and Reconstructive Surgery, Yale School of Medicine, Yale Physicians Bldg., 800 Howard Ave., 4th Fl., New Haven, CT 06511.email: john.persing@yale. edu. 